\title{
Role of Astrocytes in Epilepsy
}

\author{
Douglas A. Coulter ${ }^{1}$ and Christian Steinhäuser ${ }^{2}$ \\ ${ }^{1}$ Departments of Pediatrics and Neuroscience, Perelman School of Medicine, University of Pennsylvania \\ and the Children's Hospital of Philadelphia, Philadelphia, Pennsylvania 19104-4318 \\ ${ }^{2}$ Institute of Cellular Neurosciences, Medical Faculty, University of Bonn, 53105 Bonn, Germany \\ Correspondence: coulterd@email.chop.edu; christian.steinhaeuser@ukb.uni-bonn.de
}

\begin{abstract}
Astrocytes express ion channels, transmitter receptors, and transporters and, thus, are endowed with the machinery to sense and respond to neuronal activity. Recent studies have implicated that astrocytes play important roles in physiology, but these cells also emerge as crucial actors in epilepsy. Astrocytes are abundantly coupled through gap junctions allowing them to redistribute elevated $\mathrm{K}^{+}$and transmitter concentrations from sites of enhanced neuronal activity. Investigation of specimens from patients with pharmacoresistant temporal lobe epilepsy and epilepsy models revealed alterations in expression, localization, and function of astroglial $\mathrm{K}^{+}$and water channels. In addition, malfunction of glutamate transporters and the astrocytic glutamate-converting enzyme, glutamine synthetase, has been observed in epileptic tissue. These findings suggest that dysfunctional astrocytes are crucial players in epilepsy and should be considered as promising targets for new therapeutic strategies.
\end{abstract}

\begin{abstract}
Astrocytes are active partners in neural inAformation processing. Astrocytic processes contact the vasculature or dynamically enwrap thousands of synapses to modulate neuronal activity through the uptake and release of neurotransmitters (Halassa and Haydon 2010; Araque et al. 2014). The intimate morphological and physiological interconnection between both cell types gave rise to the concept of tripartite synapses, which comprises not only pre- and postsynaptic elements but also the astrocytic process. Astrocytes seem to be key players in fundamental brain functions, for example, in learning and memory (Henneberger et al. 2010), in the control of sleep (Halassa et al. 2009), and breathing (Gourine et al. 2010).
\end{abstract}

Despite the fact that the pathways enabling activation of astrocytes under physiological conditions are still ill determined, a critical role of astrocyte dysfunction in the pathogenesis of neurological disorders is increasingly acknowledged (Seifert et al. 2006). In this review, we will discuss recent work on neurosurgical specimens from patients with pharmacoresistant mesial temporal lobe epilepsy (MTLE) and corresponding animal models of epilepsy. Our focus will be on expression, subcellular localization, and function of astroglial $\mathrm{K}^{+}$ and water channels, gap junctions, glutamate transporters, and the glutamate-converting enzyme, glutamine synthetase (GS), in epileptic tissue.

Editors: Gregory L. Holmes and Jeffrey L. Noebels

Additional Perspectives on Epilepsy: The Biology of a Spectrum Disorder available at www.perspectivesinmedicine.org

Copyright (C) 2015 Cold Spring Harbor Laboratory Press; all rights reserved; doi: 10.1101/cshperspect.a022434

Cite this article as Cold Spring Harb Perspect Med 2015;5:a022434 
D.A. Coulter and C. Steinhäuser

\section{$\mathrm{K}^{+}$HOMEOSTASIS IS DISTURBED IN EPILEPSY}

Neuronal activity entails rapid changes of the extracellular $\mathrm{K}^{+}$concentration $\left[\mathrm{K}^{+}\right]_{\mathrm{o}}$ (Nicholson and Syková 1998). If increases in $\left[\mathrm{K}^{+}\right]_{\mathrm{o}}$ remain uncorrected, the resting potential would become more positive and affect gating of transmembrane ion channels, receptors, and transporters. During seizure activity in vivo, $\left[\mathrm{K}^{+}\right]_{\mathrm{o}}$ may increase up to a ceiling level of 10-12 mM (Heinemann and Lux 1977). Two main mechanisms are thought to balance $\left[\mathrm{K}^{+}\right]_{\mathrm{o}}$ during neuronal activity: $\mathrm{K}^{+}$uptake and spatial $\mathrm{K}^{+}$ buffering (Kofuji and Newman 2004). $\mathrm{K}^{+}$net uptake through the $\mathrm{Na}$, K-ATPase, or Na-K-Cl cotransporters produces cell swelling and local depolarization of astrocytes. In rodent hippocampus, the Na-K-ATPase has a role in maintaining low $\left[\mathrm{K}^{+}\right]_{\mathrm{o}}$ levels and in clearing elevations in $\left[\mathrm{K}^{+}\right]_{\mathrm{o}}$ after epileptiform activity (Xiong and Stringer 2000; D'Ambrosio et al. 2002). Whether alterations in net $\mathrm{K}^{+}$uptake contribute to the enhanced $\left[\mathrm{K}^{+}\right]_{\mathrm{o}}$ levels seen in epileptic tissue is still unclear. Spatial $\mathrm{K}^{+}$buffering instead is driven by the spatial gradients in membrane potential and $\mathrm{K}^{+}$equilibrium potential within the coupled glial network, which allows transfer of $\mathrm{K}^{+}$from regions of elevated $\left[\mathrm{K}^{+}\right]_{\mathrm{o}}$ through the syncytium, to regions of lower $\left[\mathrm{K}^{+}\right]_{\mathrm{o}}$. Spatial buffering depends on distribution and function of astrocytic $\mathrm{K}^{+}$channels, water channels, and gap junctions (Fig. 1) (Kofuji and Newman 2004). It has been reported that the redistribution of $\mathrm{K}^{+}$is preserved in the hippocampal stratum radiatum (but not in the lacunosum-moleculare) of mice with coupling deficient astrocytes, indicating that gap-junction-independent mechanisms add to $\left[\mathrm{K}^{+}\right]_{\mathrm{o}}$ regulation in the brain (Wallraff et al. 2006).

Because of its presumed role in $\mathrm{K}^{+}$homeostasis, properties of Kir channels in astrocytes have been investigated in experimental and human epilepsy. $\left[\mathrm{K}^{+}\right]_{\mathrm{o}}$ assessment with ion-sensitive microelectrodes, and patch-clamp studies suggested that the impaired $\mathrm{K}^{+}$buffering in sclerotic human hippocampus resulted from impaired Kir channel expression. Differences were observed in the effect of $\mathrm{Ba}^{2+}$ on stimu- lus-induced changes in $\left[\mathrm{K}^{+}\right]_{\mathrm{o}}$ in brain slices from MTLE patients with (MTLE-hippocampal sclerosis [HS]) or without hippocampal sclerosis (non-HS). In non-HS tissue, $\mathrm{Ba}^{2+}$ enhanced $\left[\mathrm{K}^{+}\right]_{\mathrm{o}}$, although this effect was not observed in MTLE-HS specimens. Because $\mathrm{Ba}^{2+}$ is a blocker of Kir channels and Kir currents are predominantly expressed by astrocytes (Seifert et al. 2009), this finding suggested impaired function of these channels in sclerotic tissue (Kivi et al. 2000). The hypothesis could be confirmed with patch clamp analyses showing decreased Kir currents in MTLE-HS patients (Bordey and Sontheimer 1998; Hinterkeuser et al. 2000). It was concluded that in MTLE-HS, disturbed $\mathrm{K}^{+}$ buffering and enhanced seizure susceptibility result from reduced expression of Kir channels (Fig. 1). Kir4.1 is the main $\mathrm{K}^{+}$channel subunit of astrocytes in rodent and human hippocampus (Schröder et al. 2000; Olsen and Sontheimer 2008; Seifert et al. 2009), and Western blot (Das et al. 2012), and immunohistochemistry (Heuser et al. 2012) confirmed a significant loss of Kir4.1 protein in human MTLE-HS. Whether these changes are cause or consequence of the epileptic condition remains to be elucidated.

Down-regulation of Kir4.1 reduced the ability of astrocytes to remove glutamate and $\mathrm{K}^{+}$ from the extracellular space (Djukic et al. 2007; Kucheryavykh et al. 2007). General knockout of Kir4.1 leads to early postnatal lethality (Kofuji et al. 2000), whereas mice with astrocytic channel deletion display epilepsy (Chever et al. 2010; Haj-Yasein et al. 2011). Traumatic brain injury (TBI) leads to impaired $\mathrm{K}^{+}$homeostasis (D'Ambrosio et al. 1999) and spontaneous partial seizures in the neocortex and hippocampus (D'Ambrosio et al. 2005). Immunohistochemistry postinjury revealed loss of Kir4.1 in the processes of astrocytes attributable to serum extravasation accompanying TBI (Stewart et al. 2010). Dysfunction of the blood-brain barrier (BBB) is also involved in seizure generation (reviewed by Kovacs et al. 2012). Transient opening of the BBB is sufficient for induction of focal epileptogenesis (Seiffert et al. 2004). BBB lesions are initial events in human MTLE, leading to the extravasation of serum albumin, which is 


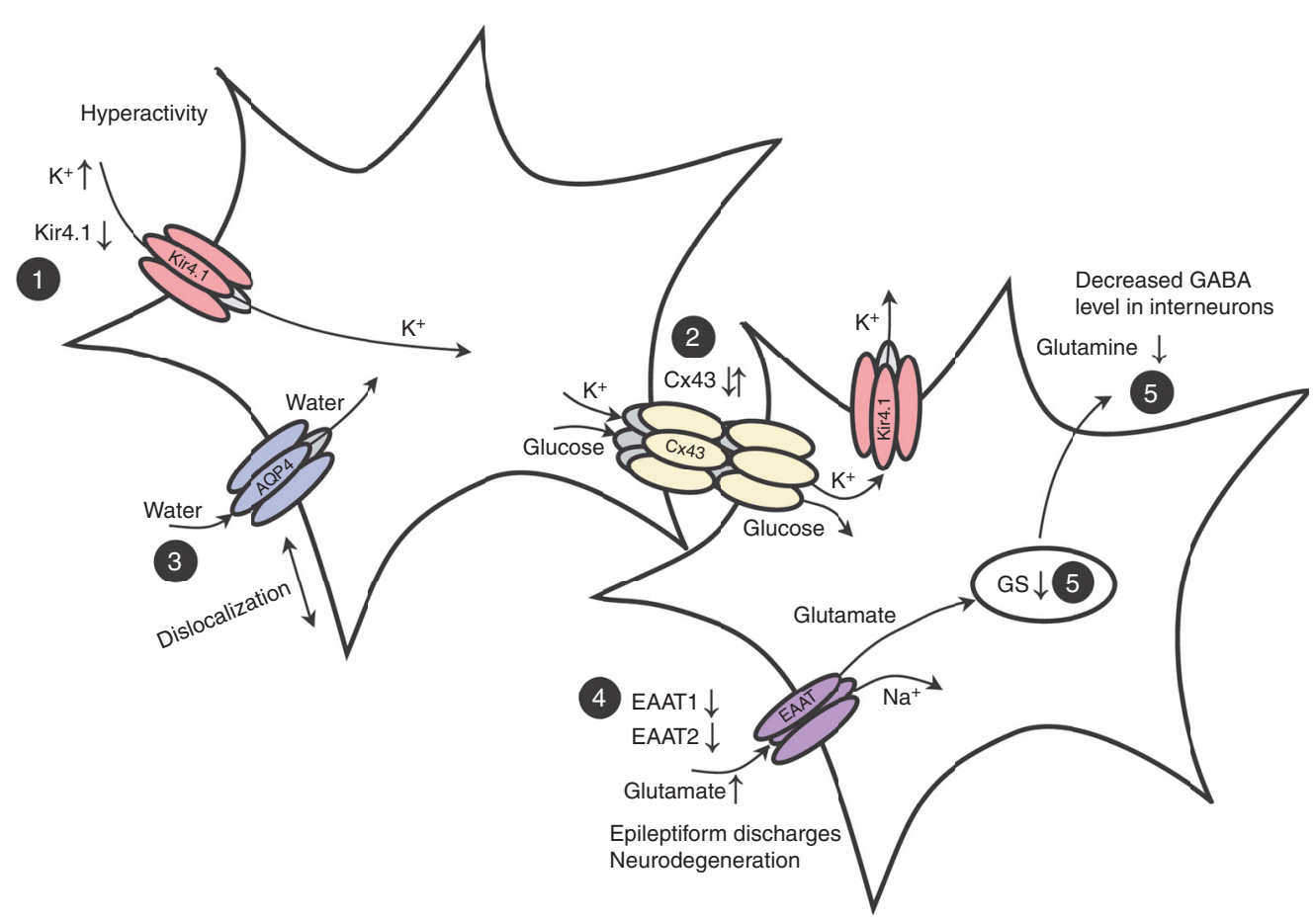

Figure 1. Astrocytic dysfunction in mesial temporal lobe epilepsy with hippocampal sclerosis (MTLE-HS). (1) Seizure activity leads to an increase in extracellular $\mathrm{K}^{+}$concentration. Down-regulation of Kir channels was observed in astrocytes in human and experimental epilepsy. (2) Gap junctions mediate spatial redistribution of $\mathrm{K}^{+}$and energy metabolites. It is still unclear whether gap-junction communication in MTLE-HS is impaired and contributes to seizure generation or seizure spread. (3) Dislocation of water channels contributes to impaired $\mathrm{K}^{+}$buffering. (4) Astrocytes mediate glutamate uptake. Reduced expression of the astrocytic transporters (EAAT1, EAAT2) was observed in human epileptic hippocampus. Elevated extracellular glutamate decreases the threshold for seizure induction. (5) Glutamate is converted into glutamine through glutamine synthetase (GS). In chronic epileptic hippocampus, loss of GS-impaired extracellular glutamate clearance and glutamine supply to neurons, resulting in decreased $\gamma$-aminobutyric acid (GABA) release and hyperactivity. AQP4, Aquaporin 4. (From Seifert and Steinhäuser 2013; modified, with permission, from Elsevier (C) 2013.)

taken up by neurons, astrocytes, and microglia (Seiffert et al. 2004; Van Vliet et al. 2007; Braganza et al. 2012). Albumin uptake by astrocytes involves transforming growth factor (TGF)- $\beta$ receptors, resulting in down-regulation of Kir4.1 and Kir2.3 channels, impaired gap junction coupling and $\mathrm{K}^{+}$buffering, and hyperexcitability (Friedman et al. 2009; Braganza et al. 2012). No changes in astrocytic Kir currents were found in a kainate model of epilepsy (Takahashi et al. 2010). Recently, down-regulation of Kir4.1 mRNA and protein has been reported in the context of epilepsy and inflammation, possibly mediated by the proinflammatory cytokine interleukin (IL)-1 $\beta$ (Zurolo et al. 2012), whereas another study reported enhanced Kir4.1 expression in a rat pilocarpine model (Nagao et al. 2013). Unfortunately, functional consequences of these changes have not been assessed in the latter two studies.

Linkage analysis in children with seizures, ataxia, sensoneural deafness, mental retardation, and electrolytic imbalance (SeSAME or EAST syndrome) identified KCNJ10 as a candidate gene, which encodes Kir4.1 (Bockenhauer et al. 2009; Scholl et al. 2009). Sequencing of the affected KCNJ10 gene revealed loss-offunction mutations of the channel, and heterologous expression confirmed that the mutations affected Kir4.1 function and produced depolari- 
D.A. Coulter and C. Steinhäuser

zation (Bockenhauer et al. 2009; Scholl et al. 2009; Reichold et al. 2010; Williams et al. 2010). The mutations increased the $\mathrm{pH}_{\mathrm{i}}$-sensitivity of the channel and impeded its surface expression (Sala-Rabanal et al. 2010; Williams et al. 2010). In patients carrying a gain-of-function of KCNJ10 heterozygous mutations were localized to the amino terminus and the first transmembrane region of the channel protein. Afflicted patients presented with seizures, autism spectrum disorders, and intellectual disability (Sicca et al. 2011).

\section{ALTERATIONS OF AQUAPORIN-4 IN EPILEPSY}

Developmental maturation of aquaporin-4 (AQP4) and Kir4.1 expression occurs within the same postnatal time window. Compared with the rather uniform distribution of Kir4.1, AQP4 displays a pronounced laminar profile, with strong expression in vascular regions (i.e., the hippocampal stratum lacunosum-moleculare and stratum-moleculare of the dentate gyrus). The time course of AQP4 and Kir4.1 up-regulation parallels the reduction of the extracellular space, emphasizing their impact for $\mathrm{K}^{+}$homeostasis (Hsu et al. 2007, 2011; Seifert et al. 2009). Ultrastructural analyses showed spatial overlap of Kir4.1 and the water channel AQP4 in astroglial endfeet (Nielsen et al. 1997; Higashi et al. 2001), and suggested that $\mathrm{K}^{+}$clearance through Kir channels might depend on transmembrane flux of water dissipating osmotic imbalances because of $\mathrm{K}^{+}$redistribution. In line with this idea, clearance of extracellular $\mathrm{K}^{+}$ was compromised if the number of perivascular AQP4 channels decreased (Amiry-Moghaddam et al. 2003b), and impaired $\mathrm{K}^{+}$buffering and prolonged seizures occurred in AQP4 knockout mice (Binder et al. 2006). However, spatial $\mathrm{K}^{+}$ redistribution was more efficient in the absence of AQP4, probably because of enhanced astroglial gap-junction coupling and volume regulation (Benfenati et al. 2011; Strohschein et al. 2011), and AQP4-independent Kir4.1 function has been confirmed (Ruiz-Ederra et al. 2007; Zhang and Verkman 2008).
MTLE-HS patients showed loss of AQP4 immunoreactivity in vasculature-associated astrocyte endfeet (Eid et al. 2005). In patients presenting with focal cortical dysplasia and epilepsy (FCD type IIB), higher AQP4 expression was found in the neuropil and around dysplastic neurons while immunoreactivity around blood vessels was also decreased (Medici et al. 2011). This decrease of perivascular AQP4 channels might be secondary, following disruption of the dystrophin complex that is essential for membrane anchoring of AQP4 (Amiry-Moghaddam et al. 2003a; Kim et al. 2010). Recently, a kainate model of MTLE was used to investigate whether the observed loss of perivascular AQP4 is involved in epileptogenesis or merely represents a compensatory effect of the condition. The data show that AQP4 mislocalization precedes the chronic phase of the disorder, indicating its pathophysiological relevance.

Patients with MTLE-HS and antecedent febrile seizures (FS) carry single nucleotide polymorphisms (SNPs) in their AQP4 and KCNJ10 genes. Multivariate analysis identified a correlation between SNPs in these two genes and the incidence of MTLE-HS with FS (Heuser et al. 2010). One of the SNPs in the KCNJ10 gene was associated with seizure resistance (Buono et al. 2004; Lenzen et al. 2005).

Together, these findings suggest that, in MTLE, dislocation of AQP4 channels in concert with decreased expression of Kir channels in astrocytes contribute to impaired $\mathrm{K}^{+}$buffering and increased seizure propensity (Fig. 1).

\section{A ROLE FOR ALTERED GAP-JUNCTION COUPLING IN EPILEPSY?}

The abundant expression of gap junctions in astrocytes and their formation as a functional network enables long-range intercellular exchange of ions, metabolites, amino acids, and nucleotides. Astrocytic gap junctions are mainly formed by connexin (Cx) 43 and Cx30. Intercellular trafficking of glucose through the astrocytic network and delivery of energetic metabolites from blood vessels to neurons is important to maintain synaptic activity (Rouach et al. 2008), but also to enable spatial redistribu- 
tion of $\mathrm{K}^{+}$and glutamate (Wallraff et al. 2006). Accordingly, astrocyte gap-junction coupling in principle may exert pro- as well as antiepileptic effects.

The role of interastrocytic coupling in the development and progression of epilepsy is still elusive. The reason behind this unsatisfactory situation is the fact that, despite various connexin expression studies, virtually no information is available about functional coupling of astrocytes under this condition. With regard to the expression studies, enhanced, decreased, or unaltered expression of connexin 43 and/or Cx30 transcripts and protein has all been reported, both in human epilepsy and in various animal models (reviewed in Giaume et al. 2010; Steinhäuser et al. 2012). However, Cx expression does not necessarily reflect functional coupling because posttranslational modifications may alter unitary conductance, open probability, trafficking, or internalization, making functional coupling analyses indispensable.

Unfortunately, not a single study has yet investigated functional coupling of astrocytes in human epilepsy, whereas findings from animal models are conflicting. In a kainate model and in hippocampal slice cultures chronically exposed to the $\mathrm{GABA}_{\mathrm{A}}$ receptor antagonist, bicuculline, increased astrocytic coupling has been reported (Samoilova et al. 2003; Takahashi et al. 2010). In contrast, $\mathrm{Xu}$ et al. (2009) observed decreased coupling in the hippocampal CA1 region in a tuberous sclerosis epilepsy model.

Another approach to assess gap-junction coupling in epilepsy is pharmacological inhibition of interastrocytic communication. Such experiments have been performed in a variety of in vivo and in vitro models of epilepsy (Perez-Velazquez et al. 1994; Ross et al. 2000; Kohling et al. 2001; Jahromi et al. 2002; Szente et al. 2002; Gajda et al. 2003; Samoilova et al. 2003, 2008; Bostanci and Bagirici 2006, 2007; Medina-Ceja et al. 2008; Voss et al. 2009). Most of these studies reported anticonvulsive effects of gap-junction blockade although opposite effects were observed by Voss et al. (2009). In neocortical slices from patients with MTLE or focal cortical dysplasia, gap-junction inhibitors attenuated epileptiform activity (Gigout et al. 2006). Major problems with gap-junction blockers are their significant side effects and poor Cx isoform(and, hence, cell-type-) specificity, which complicate interpretation of these experiments.

In conclusion, $\mathrm{Cx}$ expression studies and functional coupling analyses yield an inconsistent picture of the role of the astroglial network in the pathophysiology of epilepsy (Fig. 1). Systematic coupling analysis at different time points during experimental epileptogenesis and in human epileptic specimens is urgently needed to clarify this important question.

\section{GLUTAMATE UPTAKE AND EPILEPSY}

Uptake of glutamate is mainly mediated by transporters localized at astrocytic membranes, and altered activity of the astrocytic transporters, EAAT1 and EAAT2, seems to be a common feature of epilepsy and other brain disorders (Seifert et al. 2006). Excess of extracellular glutamate characterizes human epileptic tissue and induces recurrent seizures and neuronal death (Fig. 1) (Glass and Dragunow 1995).

Our picture about the regulation of glial glutamate transporters in human epilepsy is inconsistent. Using in situ hybridization and Western blot in specimens from MTLE-HS patients, Tessler et al. (1999) and Eid et al. (2004) did not find changes of EAAT1 or EAAT2. In contrast, other groups reported down-regulation of EAAT2 in the CA1 region in human HS (Mathern et al. 1999; Proper et al. 2002). Increased EAAT1 levels were noted in the sclerotic CA2/3 region (Mathern et al. 1999), whereas later work showed down-regulation of EAAT1 and EAAT2 in the CA1 region in MTLEHS (Fig. 1), and emphasized that it remained unclear whether this reduction was causative of the condition or of compensatory nature (Sarac et al. 2009). Epilepsy patients presenting with focal cortical dysplasia (FCD) showed lower EAAT-1 and EAAT-2 immunoreactivity and more diffuse expression patterns as compared with idiopathic epilepsy cases or postmortem controls (Ulu et al. 2010). $\beta$-Lactam antibiotics increase glutamate uptake in astrocytes through NF-кB-mediated EAAT2-promoter activation, which might represent a therapeutic tool to 
counteract glutamate transporter dysfunction (Lee et al. 2008).

In a model of cortical dysplasia, pharmacological inhibition of glial glutamate transporters in the lesion area provoked opening of neuronal $\mathrm{N}$-methyl-D-aspartate (NMDA) receptors, prolonged synaptic currents, and decreased the threshold for the induction of epileptiform activity (Campbell and Hablitz 2008). Accelerated astrocytic glutamate uptake was observed after kainate-induced status epilepticus (SE) (Takahashi et al. 2010). In the hippocampus of spontaneously epileptic rats, EAAT1 transcripts and protein were decreased, whereas EAAT2 remained unaffected (Guo et al. 2010). Inhibition of glutamate transporters shortened the latency for onset of epileptiform discharges in a low $\mathrm{Mg}^{2+}$ slice model, suggesting a role for ambient glutamate in the genesis and maintenance of seizure activity (Nyitrai et al. 2010).

\section{GLUTAMATE DEGRADATION}

Once taken up by astrocytes via glutamate transporters (discussed above), glutamate must be sequestered and degraded. This is because glutamate transporters are inherently bidirectional, so intracellular elevations of glutamate concentration within astrocytes will ultimately lead to its electrochemical gradient-mediated release. Failure to degrade glutamate leads to its extracellular accumulation, which has deleterious effects on the function and survival of neurons. In addition, because synaptic terminals are at remote locations from the cell bodies of neurons, this necessitates there to be a local economy at synapses requiring proximate recycling of neurotransmitter for continued function. Once inactivated, neurotransmitter intermediaries must be shuttled back to synapses where an appropriate neurotransmitter can be regenerated through mitochondrial enzymes.

Part of this glutamate degradation process is accomplished through the activity of glutamate dehydrogenase, which catalyzes the formation of $\alpha$-ketoglutarate from glutamate, providing an intermediary in the tricarboxylic acid (TCA) cycle. This allows its use as a metabolic fuel (Dennis et al. 1977). A second prevalent pathway involves the keystone enzyme in the glutamate degradation process, GS, which is localized predominantly in astrocytes in the brain. GS catalyzes the enzymatic conversion of glutamate to glutamine. Glutamine is then shuttled to neurons via specific glutamine transporters, where it can be reconverted to glutamate by the mitochondrial enzyme, phosphate-activated glutaminase. In addition to its pivotal role in ammonia detoxification, the glutamine-glutamate cycle is critical in the synthesis of neuronal glutamate for use as a neurotransmitter (van den Berg and Garfinkel 1971; Benjamin and Quastel 1975; Tani et al. 2014), and, in interneurons, of subsequent decarboxylation of glutamate to form the inhibitory neurotransmitter, GABA, via the glutamine-glutamate-GABA cycle (Liang et al. 2006; Fricke et al. 2007; Yang and Cox 2011).

\section{GLUTAMINE-GLUTAMATE-GABA CYCLES IN TEMPORAL LOBE EPILEPSY}

In patients with temporal lobe epilepsy (TLE), there are abnormally high concentrations of extracellular glutamate, both during and between seizure episodes (i.e., in both ictal and interictal periods) (During and Spencer 1993; Petroff et al. 2004; Cavus et al. 2005). This elevation of extracellular glutamate is much more evident in patients with HS (gliosis) than in patients without sclerosis (Kim et al. 2004; Petroff et al. 2004). Perhaps causally related to this elevated extracellular glutamate concentration in hippocampus of patients with TLE, in tissue resected from these patients there is a significant loss of GS in astrocytes, as well as a significant reduction in GS enzymatic activity (Fig. 1) (Eid et al. 2004; van der Hel et al. 2005). This downregulation in GS expression and function in hippocampus of epilepsy patients is accompanied by changes in expression and function of astrocytic glutamate transporters, as discussed above.

These static, neuropathological and biochemical findings in patients raise the related questions. Are GS changes (and concomitant disrupted function of the glutamine-glutamate cycle) a cause or a consequence of epilepsy? Do 
they contribute to ongoing pathological function, or are they a reflection of excitotoxic damage associated with aberrant activity? These have been addressed, in part, by a series of studies in experimental systems. A first set of experiments centered on the chicken/egg question regarding GS down-regulation in epilepsy, which is, is compromised expression of GS an epiphenomenon, or a causative factor in TLE? To address this, Eid and colleagues continuously infused the GS antagonist, methionine sulfoximine (MSO) into the hippocampus of rats for 28 days, and examined the consequences on epilepsy development (Eid et al. 2008; Wang et al. 2009). They found that animals treated with MSO developed epilepsy and neuropathological features similar to MTLE-HS, supporting a role for GS down-regulation in the pathogenesis of the epileptic condition.

\section{CONSEQUENCES OF GS DOWN- REGULATION ON SYNAPTIC TRANSMISSION AND CIRCUIT EXCITABILITY}

In addition to contributing to extracellular glutamate accumulation in the sclerotic hippocampus of TLE patients, a series of recent studies have suggested that GS down-regulation and disruption of the glutamine-glutamate cycle may also have significant effects on hippocampal circuit excitability by differential effects on inhibitory and excitatory synaptic function.

The glutamine-glutamate cycle begins with the uptake of synaptically released glutamate by glutamate transporters in ensheathing astrocytic processes. Glutamate is converted to glutamine via GS inside astrocytes. Glutamine is then shuttled back to presynaptic terminals of neurons through specific glutamine transporters localized in astrocytes and neurons. In nerve terminals, glutamine is reconverted to glutamate through the activity of phosphate-activated glutaminase in mitochondria. Glutamate is available directly as a neurotransmitter for packaging in synaptic vesicles in excitatory terminals, or is converted to GABA by decarboxylation in inhibitory terminals (the glutamineglutamate-GABA cycle). Release of synaptic glutamate then completes the cycle (reviewed in Chaudry et al. 2002; Bak et al. 2006).

Given the nature of the glutamine-glutamate cycle and the local neurotransmitter economy in synapses, it would be expected that interfering with the cycle at any stage would rapidly impact neurotransmitter supply, and synaptic function. This was found to be the case for hippocampal and thalamic inhibitory synapses, in which application of GS antagonists, glutamate uptake blockers, or glutamine transporter blockers all rapidly depleted synaptic release of GABA, which could be reversed by supply of exogenous glutamine (Liang et al. 2006; Fricke et al. 2007; Yang and Cox 2011). Surprisingly, excitatory synaptic transmission is much less sensitive to disruption of the glutamine-glutamate cycle. In studies examining the effects of glutamine-glutamate cycle blockades, little compromise in excitatory synaptic function was evident until protracted periods of synaptic release had occurred (Kam and Nicoll 2007; Tani et al. 2014). This may be because of higher reserve pools of cytoplasmic glutamate being accessible to excitatory neurons, buffering the immediate effects of loss of glutamine-glutamate cycle function. However, the net interpretation of these studies is clear. In situations, in which the glutamine-glutamate cycle is compromised (as occurs with loss of GS expression in epilepsy), the predominant proximate effect may be to reduce GABA release from inhibitory synapses, enhancing circuit excitability.

This line of experimentation has been extended to explore the potential role of astrogliosis in excitability defects underlying seizure predisposition in TLE. Reactive gliosis develops in many neurologic disorders, including, notably, epilepsy and, as was discussed above, is associated with a down-regulation in GS expression. However, the role astroglial reactivity may play in the etiology of epilepsy and other neurologic conditions is poorly understood, in part because of the numerous additional, potentially contributory changes evident following an epileptogenic injury. To isolate the role reactive astrogliosis may play in generating excitability defects in hippocampal circuits, Ortinski et al. (2010) induced reactive astrocytosis using a cell- 
specific viral strategy, and then studied the effects of gliosis on circuit excitability.

Virally induced astrogliosis shared many of the hallmarks of reactivity seen in vivo: virally treated astrocytes showed hypertrophy accompanied by increased vimentin and glial fibrillary acidic protein (GFAP) expression, and a downregulation in GS expression. Notably, neighboring neurons showed no alterations in their anatomy and intrinsic properties. In regions with virally transduced, reactive astrocytes, GABAergic inhibition, but not glutamatergic excitation, was significantly compromised (Fig. 1), and circuit excitability was enhanced in area CA1 of the hippocampus, specifically evident as hyperactivation of direct cortical inputs to the distal dendrites of CA1 neurons (Ortinski et al. 2010). This pathway has been previously shown to be extensively regulated by local circuit inhibition (Empson and Heinemann 1995; Soltesz 1995; Ang et al. 2005), and to be extensively hyperactive in epileptic animals (Denslow et al. 2001; Wozny et al. 2005; Ang et al. 2006). Importantly, all of these astrogliosis-mediated effects could be mimicked by blockers of the glutamine-glutamate cycle and occluded by these same blockers, and were reversed by a supply of exogenous glutamine, supporting a role for gliosis-induced GS down-regulation in the circuit excitability defects underlying epilepsy.

\section{CONCLUDING REMARKS}

The pivotal role played by astrocytes in regulating normal brain functions clearly extends to a pathophysiologic role in epilepsy. As is discussed above, astrocytes play a number of essential roles in brain function, including regulation of $\mathrm{K}^{+}$and glutamate homeostasis, as well as in the supply of neurotransmitter precursors for reuse at excitatory and inhibitory synapses. These normal functions are all significantly perturbed in epilepsy. Associated with the development of gliosis in the brains of patients with epilepsy and in animal models of this disorder, there is accumulating evidence for loss of appropriate $\mathrm{K}^{+}$homeostasis and accompanying changes in aquaporin, gap-junction expression and function, compromised uptake and metab- olism of glutamate in astrocytes, and disrupted neurotransmitter supply, particularly in inhibitory neurons. In addition to being potentially linked with gliosis, these biochemical changes have significant functional consequences, contributing to the circuit hyperexcitability that is the hallmark of epilepsy. This further implicates compromised astrocyte dysfunction in the pathophysiology of epilepsy. In addition to providing new information about causal factors in epilepsy development and expression, this role of astrocytes suggests new avenues for therapeutic interventions with significant promise.

\section{ACKNOWLEDGMENTS}

Research of the authors is supported by the $\mathrm{Na}$ tional Institutes of Health (P01 NS054900 and P20 MH71705), the Deutsche Forschungsgemeinschaft (STE 552/3, STE 552/4), and the EU (EuroEPINOMICS). We thank Dr. I. Heuer for help with graphical work and apologize to all colleagues whose findings could not be discussed because of space constraints.

\section{REFERENCES}

Amiry-Moghaddam M, Otsuka T, Hurn PD, Traystman RJ, Haug FM, Froehner SC, Adams ME, Neely JD, Agre P, Ottersen OP, et al. 2003a. An $\alpha$-syntrophin-dependent pool of AQP4 in astroglial end-feet confers bidirectional water flow between blood and brain. Proc Natl Acad Sci 100: $2106-2111$.

Amiry-Moghaddam M, Williamson A, Palomba M, Eid T, De Lanerolle NC, Nagelhus EA, Adams ME, Froehner SC, Agre P, Ottersen OP. 2003b. Delayed $\mathrm{K}^{+}$clearance associated with aquaporin-4 mislocalization: Phenotypic defects in brains of $\alpha$-syntrophin-null mice. Proc Natl Acad Sci 100: 13615-13620.

Ang CW, Carlson GC, Coulter DA. 2005. Hippocampal CA1 circuitry dynamically gates direct cortical inputs preferentially at $\theta$ frequencies. J Neurosci 25: 9567-9580.

Ang CW, Carlson GC, Coulter DA. 2006. Massive and specific dysregulation of direct cortical inputs to the hippocampus in temporal lobe epilepsy. J Neurosci 26: 11850 11856.

Araque A, Carmignoto G, Haydon PG, Oliet SH, Robitaille R, Volterra A. 2014. Gliotransmitters travel in time and space. Neuron 81: 728-739.

Bak LK, Schousboe A, Waagepetersen HS. 2006. The glutamate/GABA-glutamine cycle: Aspects of transport, neurotransmitter homeostasis and ammonia transfer. J Neurochem 98: 641-653.

Benfenati V, Caprini M, Dovizio M, Mylonakou MN, Ferroni S, Ottersen OP, Amiry-Moghaddam M. 2011. An 
aquaporin-4/transient receptor potential vanilloid 4 (AQP4/TRPV4) complex is essential for cell-volume control in astrocytes. Proc Natl Acad Sci 108: 2563-2568.

Benjamin AM, Quastel JH. 1975. Metabolism of amino acids and ammonia in rat brain cortex slices in vitro: A possible role of ammonia in brain function. J Neurochem 25: 197-206.

Binder DK, Yao X, Zador Z, Sick TJ, Verkman AS, Manley GT. 2006. Increased seizure duration and slowed potassium kinetics in mice lacking aquaporin- 4 water channels. Glia 53: 631-636.

Bockenhauer D, Feather S, Stanescu HC, Bandulik S, Zdebik AA, Reichold M, Tobin J, Lieberer E, Sterner C, Landoure G, et al. 2009. Epilepsy, ataxia, sensorineural deafness, tubulopathy, and KCNJ10 mutations. N Engl J Med 360: $1960-1970$.

Bordey A, Sontheimer H. 1998. Properties of human glial cells associated with epileptic seizure foci. Epilepsy Res 32: 286-303.

Bostanci MO, Bagirici F. 2006. The effects of octanol on penicillin induced epileptiform activity in rats: An in vivo study. Epilepsy Res 71: 188-194.

Bostanci MO, Bagirici F. 2007. Anticonvulsive effects of carbenoxolone on penicillin-induced epileptiform activity An in vivo study. Neuropharmacology 52: 362-367.

Braganza O, Bedner P, Hüttmann K, von Staden E, Friedman A, Seifert G, Steinhäuser C. 2012. Albumin is taken up by hippocampal NG2 cells and astrocytes and decreases gap junction coupling. Epilepsia 53: 1898-1906.

Buono RJ, Lohoff FW, Sander T, Sperling MR, O'Connor MT, Dlugos DJ, Ryan SG, Golden GT, Zhao H, Scattergood TM, et al. 2004. Association between variation in the human KCNJ10 potassium ion channel gene and seizure susceptibility. Epilepsy Res 58: 175-183.

Campbell SL, Hablitz JJ. 2008. Decreased glutamate transport enhances excitability in a rat model of cortical dysplasia. Neurobiol Dis 32: 254-261.

Cavus I, Kasoff WS, Cassaday MP, Jacob R, Gueorguieva R, Sherwin RS, Krystal JH, Spencer DD, Abu-Saab WM. 2005. Extracellular metabolites in the cortex and hippocampus of epileptic patients. Ann Neurol 57: 226-235.

Chaudry FA, Reimer RJ, Edwards RH. 2002. The glutamine commute: Take the N line and transfer to the A. J Cell Biol 157: 349-355.

Chever O, Djukic B, McCarthy KD, Amzica F. 2010. Implication of kir4.1 channel in excess potassium clearance: An in vivo study on anesthetized glial-conditional kir4.1 knock-out mice. J Neurosci 30: 15769-15777.

D’Ambrosio R, Fender JS, Fairbanks JP, Simon EA, Born DE, Doyle DL, Miller JW. 2005. Progression from frontal-parietal to mesial-temporal epilepsy after fluid percussion injury in the rat. Brain 128: 174-188.

D’Ambrosio R, Gordon DS, Winn HR. 2002. Differential role of KIR channel and $\mathrm{Na}^{+} / \mathrm{K}^{+}$-pump in the regulation of extracellular $\mathrm{K}^{+}$in rat hippocampus. $J$ Neurophysiol 87: $87-102$.

D’Ambrosio R, Maris DO, Grady MS, Winn HR, Janigro D. 1999. Impaired $\mathrm{K}^{+}$homeostasis and altered electrophysiological properties of post-traumatic hippocampal glia. J Neurosci 19: 8152-8162.
Das A, Wallace GC, Holmes C, McDowell ML, Smith JA, Marshall JD, Bonilha L, Edwards JC, Glazier SS, Ray SK, et al. 2012. Hippocampal tissue of patients with refractory temporal lobe epilepsy is associated with astrocyte activation, inflammation, and altered expression of channels and receptors. Neuroscience 220: 237-246.

Dennis SC, Lai JC, Clark JB. 1977. Comparative studies on glutamate metabolism in synaptic and non-synaptic rat brain mitochondia. Biochem J 164: 727-736.

Denslow MJ, Eid T, Du F, Schwarcz R, Lothman EW, Steward O. 2001. Disruption of inhibition in area CA1 of the hippocampus in a rat model of temporal lobe epilepsy. J Neurophysiol 86: 2231-2245.

Djukic B, Casper KB, Philpot BD, Chin LS, McCarthy KD. 2007. Conditional knock-out of Kir4.1 leads to glial membrane depolarization, inhibition of potassium and glutamate uptake, and enhanced short-term synaptic potentiation. J Neurosci 27: 11354-11365.

During MJ, Spencer DD. 1993. Extracellular hippocampal glutamate and spontaneous seizure in the conscious human brain. Lancet 341: 1607-1610.

Eid T, Thomas MJ, Spencer DD, Runden-Pran E, Lai JC, Malthankar GV, Kim JH, Danbolt NC, Ottersen OP, De Lanerolle NC. 2004. Loss of glutamine synthetase in the human epileptogenic hippocampus: Possible mechanism for raised extracellular glutamate in mesial temporal lobe epilepsy. Lancet 363: 28-37.

Eid T, Lee TS, Thomas MJ, Amiry-Moghaddam M, Bjornsen LP, Spencer DD, Agre P, Ottersen OP, De Lanerolle NC. 2005. Loss of perivascular aquaporin 4 may underlie deficient water and $\mathrm{K}^{+}$homeostasis in the human epileptogenic hippocampus. Proc Natl Acad Sci 102: $1193-$ 1198.

Eid T, Ghosh A, Wang Y, Beckstrom H, Zaveri HP, Lee TS, Lai JC, Malthankkar-Phatak GH, de Lanerolle NC. 2008. Recurrent seizures and brain pathology after inhibition of glutamine synthetase in the hippocampus in rats. Brain 131: 2061-2070.

Empson RM, Heinemann U. 1995. The perforant path projection to the hippocampal area CA1 in the rat hippocampal-entorhinal cortex combined slice. J Physiol 484: 707-720.

Fricke MN, Jones-Davis DM, Mathews GC. 2007. Glutamine uptake by system A transporters maintains neurotransmitter GABA synthesis and inhibitory synaptic transmission. J Neurochem 102: 1895-1904.

Friedman A, Kaufer D, Heinemann U. 2009. Blood-brain barrier breakdown-inducing astrocytic transformation: Novel targets for the prevention of epilepsy. Epilepsy Res 85: $142-149$.

Gajda Z, Gyengesi E, Hermesz E, Ali KS, Szente M. 2003. Involvement of gap junctions in the manifestation and control of the duration of seizures in rats in vivo. Epilepsia 44: $1596-1600$.

Giaume C, Koulakoff A, Roux L, Holcman D, Rouach N. 2010. Astroglial networks: A step further in neuroglial and gliovascular interactions. Nat Rev Neurosci 11: 8799.

Gigout S, Louvel J, Kawasaki H, D'Antuono M, Armand V, Kurcewicz I, Olivier A, Laschet J, Turak B, Devaux B, et al. 2006. Effects of gap junction blockers on human neocortical synchronization. Neurobiol Dis 22: 496-508. 
D.A. Coulter and C. Steinhäuser

Glass M, Dragunow M. 1995. Neurochemical and morphological changes associated with human epilepsy. Brain Res Rev 21: 29-41.

Gourine AV, Kasymov V, Marina N, Tang F, Figueiredo MF, Lane S, Teschemacher AG, Spyer KM, Deisseroth K, Kasparov S. 2010. Astrocytes control breathing through $\mathrm{pH}-$ dependent release of ATP. Science 329: 571-575.

Guo F, Sun F, Yu JL, Wang QH, Tu DY, Mao XY, Liu R, Wu KC, Xie N, Hao LY, et al. 2010. Abnormal expressions of glutamate transporters and metabotropic glutamate receptor 1 in the spontaneously epileptic rat hippocampus. Brain Res Bull 81: 510-516.

Haj-Yasein NN, Jensen V, Vindedal GF, Gundersen GA, Klungland A, Ottersen OP, Hvalby O, Nagelhus EA. 2011. Evidence that compromised $\mathrm{K}^{+}$spatial buffering contributes to the epileptogenic effect of mutations in the human kir4.1 gene (KCNJ10). Glia 59: 1635-1642.

Halassa MM, Haydon PG. 2010. Integrated brain circuits: Astrocytic networks modulate neuronal activity and behavior. Annu Rev Physiol 72: 335-355.

Halassa MM, Florian C, Fellin T, Munoz JR, Lee SY, Abel T, Haydon PG, Frank MG. 2009. Astrocytic modulation of sleep homeostasis and cognitive consequences of sleep loss. Neuron 61: 213-219.

Heinemann U, Lux HD. 1977. Ceiling of stimulus induced rises in extracellular potassium concentration in the cerebral cortex of cat. Brain Res 120: 231-249.

Henneberger C, Papouin T, Oliet SH, Rusakov DA. 2010. Long-term potentiation depends on release of D-serine from astrocytes. Nature 463: 232-236.

Heuser K, Nagelhus EA, Tauboll E, Indahl U, Berg PR, Lien S, Nakken S, Gjerstad L, Ottersen OP. 2010. Variants of the genes encoding AQP4 and Kir4.1 are associated with subgroups of patients with temporal lobe epilepsy. Epilepsy Res 88: 55-64.

Heuser K, Eid T, Lauritzen F, Thoren AE, Vindedal GF, Tauboll E, Gjerstad L, Spencer DD, Ottersen OP, Nagelhus EA, et al. 2012. Loss of perivascular Kir4.1 potassium channels in the sclerotic hippocampus of patients with mesial temporal lobe epilepsy. J Neuropathol Exp Neurol 71: $814-825$.

Higashi K, Fujita A, Inanobe A, Tanemoto M, Doi K, Kubo T, Kurachi Y. 2001. An inwardly rectifying $\mathrm{K}^{+}$channel, Kir4.1, expressed in astrocytes surrounds synapses and blood vessels in brain. Am J Physiol Cell Physiol 281: C922-C931.

Hinterkeuser S, Schröder W, Hager G, Seifert G, Blümcke I, Elger CE, Schramm J, Steinhäuser C. 2000. Astrocytes in the hippocampus of patients with temporal lobe epilepsy display changes in potassium conductances. Eur J Neurosci 12: 2087-2096.

Hsu MS, Lee DJ, Binder DK. 2007. Potential role of the glial water channel aquaporin-4 in epilepsy. Neuron Glia Biol 3: 287-297.

Hsu MS, Seldin M, Lee DJ, Seifert G, Steinhäuser C, Binder DK. 2011. Laminar-specific and developmental expression of aquaporin- 4 in the mouse hippocampus. Neuroscience 178: 21-32.

Jahromi SS, Wentlandt K, Piran S, Carlen PL. 2002. Anticonvulsant actions of gap junctional blockers in an in vitro seizure model. J Neurophysiol 88: 1893-1902.
Kam K, Nicoll RA. 2007. Excitatory synaptic transmission persists independently of the glutamate-glutamine cycle. J Neurosci 27: 9192-9200.

Kim JH, Je S, Petroff OA, Spencer SS, Hwang JY, Spencer DD. 2004. Hippocampal glial density in temporal lobe epilepsy. Epilepsia 45: S33-S34.

Kim JE, Yeo SI, Ryu HJ, Kim MJ, Kim DS, Jo SM, Kang TC. 2010. Astroglial loss and edema formation in the rat piriform cortex and hippocampus following pilocarpine-induced status epilepticus. J Comp Neurol 518: 4612-4628.

Kivi A, Lehmann TN, Kovacs R, Eilers A, Jauch R, Meencke MH, Von Deimling A, Heinemann U, Gabriel S. 2000. Effects of barium on stimulus-induced rises of $\left[\mathrm{K}^{+}\right]_{\mathrm{o}}$ in human epileptic non-sclerotic and sclerotic hippocampal area CA1. Eur J Neurosci 12: 2039-2048.

Kofuji P, Newman EA. 2004. Potassium buffering in the central nervous system. Neuroscience 129: 1045-1056.

Kofuji P, Ceelen P, Zahs KR, Surbeck LW, Lester HA, Newman EA. 2000. Genetic inactivation of an inwardly rectifying potassium channel (Kir4.1 subunit) in mice: Phenotypic impact in retina. J Neurosci 20: 5733-5740.

Köhling R, Gladwell SJ, Bracci E, Vreugdenhil M, Jefferys JG. 2001. Prolonged epileptiform bursting induced by $0-\mathrm{Mg}^{2+}$ in rat hippocampal slices depends on gap junctional coupling. Neuroscience 105: 579-587.

Kovacs R, Heinemann U, Steinhäuser C. 2012. Mechanisms underlying blood-brain barrier dysfunction in brain pathology and epileptogenesis: Role of astroglia. Epilepsia 53: 53-59.

Kucheryavykh YV, Kucheryavykh LY, Nichols CG, Maldonado HM, Baksi K, Reichenbach A, Skatchkov SN, Eaton MJ. 2007. Downregulation of Kir4.1 inward rectifying potassium channel subunits by RNAi impairs potassium transfer and glutamate uptake by cultured cortical astrocytes. Glia 55: 274-281.

Lee SG, Su ZZ, Emdad L, Gupta P, Sarkar D, Borjabad A, Volsky DJ, Fisher PB. 2008. Mechanism of ceftriaxone induction of excitatory amino acid transporter-2 expression and glutamate uptake in primary human astrocytes. J Biol Chem 283: 13116-13123.

Lenzen KP, Heils A, Lorenz S, Hempelmann A, Hofels S, Lohoff FW, Schmitz B, Sander T. 2005. Supportive evidence for an allelic association of the human KCNJ10 potassium channel gene with idiopathic generalized epilepsy. Epilepsy Res 63: 113-118.

Liang S-L, Carlson GC, Coulter DA. 2006. Dynamic regulation of synaptic GABA release by the glutamate-glutamine cycle in hippocampal area CA1. J Neurosci 26: 8537-8548.

Mathern GW, Mendoza D, Lozada A, Pretorius JK, Dehnes Y, Danbolt NC, Nelson N, Leite JP, Chimelli L. 1999. Hippocampal GABA and glutamate transporter immunoreactivity in patients with temporal lobe epilepsy. Neurology 52: 453-472.

Medici V, Frassoni C, Tassi L, Spreafico R, Garbelli R. 2011. Aquaporin 4 expression in control and epileptic human cerebral cortex. Brain Res 1367: 330-339.

Medina-Ceja L, Cordero-Romero A, Morales-Villagran A. 2008. Antiepileptic effect of carbenoxolone on seizures induced by 4-aminopyridine: A study in the rat hippocampus and entorhinal cortex. Brain Res 1187: 74-81. 
Nagao Y, Harada Y, Mukai T, Shimizu S, Okuda A, Fujimoto M, Ono A, Sakagami Y, Ohno Y. 2013. Expressional analysis of the astrocytic Kir4.1 channel in a pilocarpine-induced temporal lobe epilepsy model. Front Cell Neurosci 7: 104 .

Nicholson C, Syková E. 1998. Extracellular space structure revealed by diffusion analysis. Trends Neurosci 21: $207-$ 215.

Nielsen S, Nagelhus EA, Amiry-Moghaddam M, Bourque C, Agre P, Ottersen OP. 1997. Specialized membrane domains for water transport in glial cells: High-resolution immunogold cytochemistry of aquaporin-4 in rat brain. J Neurosci 17: 171-180.

Nyitrai G, Lasztoczi B, Kardos J. 2010. Glutamate uptake shapes low- $\left[\mathrm{Mg}^{2+}\right]$-induced epileptiform activity in juvenile rat hippocampal slices. Brain Res 1309: 172-178.

Olsen M, Sontheimer H. 2008. Functional implications for Kir4.1 channels in glial biology: From $\mathrm{K}^{+}$buffering to cell differentiation. J Neurochem 107: 589-601.

Ortinski PO, Dong J, Mungenast A, Yue C, Takano H, Watson DJ, Haydon PG, Coulter DA. 2010. Selective induction of astrocytic gliosis generates deficits in neuronal inhibition. Nat Neurosci 13: 584-591.

Perez-Velazquez JL, Valiante TA, Carlen PL. 1994. Modulation of gap junctional mechanisms during calcium-free induced field burst activity: A possible role for electrotonic coupling in epileptogenesis. J Neurosci 14: 43084317.

Petroff OA, Cavus I, Kim JH, Spencer DD. 2004. Interictal extracellular glutamate concentrations are increased in hippocampal sclerosis. Ann Neurol 56: S43.

Proper EA, Hoogland G, Kappen SM, Jansen GH, Rensen MG, Schrama LH, van Veelen CW, van Rijen PC, van Nieuwenhuizen O, Gispen WH, et al. 2002. Distribution of glutamate transporters in the hippocampus of patients with pharmaco-resistant temporal lobe epilepsy. Brain 125: $32-43$.

Reichold M, Zdebik AA, Lieberer E, Rapedius M, Schmidt K, Bandulik S, Sterner C, Tegtmeier I, Penton D, Baukrowitz T, et al. 2010. KCNJ10 gene mutations causing EAST syndrome (epilepsy, ataxia, sensorineural deafness, and tubulopathy) disrupt channel function. Proc Natl Acad Sci 107: 14490-14495.

Ross FM, Gwyn P, Spanswick D, Davies SN. 2000. Carbenoxolone depresses spontaneous epileptiform activity in the CA1 region of rat hippocampal slices. Neuroscience 100: 789-796.

Rouach N, Koulakoff A, Abudara V, Willecke K, Giaume C. 2008. Astroglial metabolic networks sustain hippocampal synaptic transmission. Science 322: 1551-1555.

Ruiz-Ederra J, Zhang H, Verkman AS. 2007. Evidence against functional interaction between aquaporin- 4 water channels and Kir4.1 $\mathrm{K}^{+}$channels in retinal Müller cells. J Biol Chem 282: 21866-21872.

Sala-Rabanal M, Kucheryavykh LY, Skatchkov SN, Eaton MJ, Nichols CG. 2010. Molecular mechanisms of EAST/ SeSAME syndrome mutations in Kir4.1 (KCNJ10). J Biol Chem 285: 36040-36048.

Samoilova M, Li J, Pelletier MR, Wentlandt K, Adamchik Y, Naus CC, Carlen PL. 2003. Epileptiform activity in hippocampal slice cultures exposed chronically to bicucul- line: Increased gap junctional function and expression. J Neurochem 86: 687-699.

Samoilova M, Wentlandt K, Adamchik Y, Velumian AA, Carlen PL. 2008. Connexin 43 mimetic peptides inhibit spontaneous epileptiform activity in organotypic hippocampal slice cultures. Exp Neurol 210: 762-775.

Sarac S, Afzal S, Broholm H, Madsen FF, Ploug T, Laursen H. 2009. Excitatory amino acid transporters EAAT-1 and EAAT-2 in temporal lobe and hippocampus in intractable temporal lobe epilepsy. APMIS 117: 291-301.

Scholl UI, Choi M, Liu T, Ramaekers VT, Hausler MG, Grimmer J, Tobe SW, Farhi A, Nelson-Williams C, Lifton RP. 2009. Seizures, sensorineural deafness, ataxia, mental retardation, and electrolyte imbalance (SeSAME syndrome) caused by mutations in KCNJ10. Proc Natl Acad Sci 106: $5842-5847$.

Schröder W, Hinterkeuser S, Seifert G, Schramm J, Jabs R, Wilkin GP, Steinhäuser C. 2000. Functional and molecular properties of human astrocytes in acute hippocampal slices obtained from patients with temporal lobe epilepsy. Epilepsia 41: S181-S184.

Seifert G, Steinhäuser C. 2013. Neuron-astrocyte signaling and epilepsy. Exp Neurol 244: 4-10.

Seifert G, Schilling K, Steinhäuser C. 2006. Astrocyte dysfunction in neurological disorders: A molecular perspective. Nat Rev Neurosci 7: 194-206.

Seifert G, Hüttmann K, Binder DK, Hartmann C, Wyczynski A, Neusch C, Steinhäuser C. 2009. Analysis of astroglial $\mathrm{K}^{+}$channel expression in the developing hippocampus reveals a predominant role of the Kir4.1 subunit. J Neurosci 29: 7474-7488.

Seiffert E, Dreier JP, Ivens S, Bechmann I, Tomkins O, Heinemann U, Friedman A. 2004. Lasting blood-brain barrier disruption induces epileptic focus in the rat somatosensory cortex. J Neurosci 24: 7829-7836.

Sicca F, Imbrici P, D’Adamo MC, Moro F, Bonatti F, Brovedani P, Grottesi A, Guerrini R, Masi G, Santorelli FM, et al. 2011. Autism with seizures and intellectual disability: Possible causative role of gain-of-function of the inwardly-rectifying $\mathrm{K}^{+}$channel Kir4.1. Neurobiol Dis 43: 239247.

Soltesz I. 1995. Brief history of cortico-hippocampal time with a special reference to the direct entorhinal input to CA1. Hippocampus 5: 120-124.

Steinhäuser C, Seifert G, Bedner P. 2012. Astrocyte dysfunction in temporal lobe epilepsy: $\mathrm{K}^{+}$channels and gap junction coupling. Glia 60: 1192-1202.

Stewart TH, Eastman CL, Groblewski PA, Fender JS, Verley DR, Cook DG, D’Ambrosio R. 2010. Chronic dysfunction of astrocytic inwardly rectifying $\mathrm{K}^{+}$channels specific to the neocortical epileptic focus after fluid percussion injury in the rat. J Neurophysiol 104: 3345-3360.

Strohschein S, Hüttmann K, Gabriel S, Binder DK, Heinemann U, Steinhäuser C. 2011. Impact of aquaporin-4 channels on $\mathrm{K}^{+}$buffering and gap junction coupling in the hippocampus. Glia 59: 973-980.

Szente M, Gajda Z, Said AK, Hermesz E. 2002. Involvement of electrical coupling in the in vivo ictal epileptiform activity induced by 4 -aminopyridine in the neocortex Neuroscience 115: 1067-1078. 
D.A. Coulter and C. Steinhäuser

Takahashi DK, Vargas JR, Wilcox KS. 2010. Increased coupling and altered glutamate transport currents in astrocytes following kainic-acid-induced status epilepticus. Neurobiol Dis 40: 573-585.

Tani H, Dulla CG, Farzampour Z, Taylor-Weiner A, Huguenard JR, Reimer RJ. 2014. A local glutamate-glutamine cycle sustains synaptic excitatory transmitter release. Neuron 81: 888-900.

Tessler S, Danbolt NC, Faull RLM, Storm-Mathisen J, Emson PC. 1999. Expression of the glutamate transporters in human temporal lobe epilepsy. Neuroscience 88: $1083-$ 1091.

Ulu MO, Tanriverdi T, Oz B, Biceroglu H, Isler C, Eraslan BS, Ozkara C, Ozyurt E, Uzan M. 2010. The expression of astroglial glutamate transporters in patients with focal cortical dysplasia: An immunohistochemical study. Acto Neurochir (Wien) 152: 845-853.

van den Berg CJ, Garfinkel D. 1971. A stimulation study of brain compartments. Metabolism of glutamate and related substances in mouse brain. Biochem J 123: 211-218.

van den Hel WS, Notenboom RG, Bos IW, van Rijen PC, van Veelen CW, de Graan PN. 2005. Reduced glutamine synthetase in hippocampal areas with neuron loss in temporal lobe epilepsy. Neurology 64: 326-333.

Van Vliet EA, da Costa AS, Redeker S, van Schaik R, Aronica E, Gorter JA. 2007. Blood-brain barrier leakage may lead to progression of temporal lobe epilepsy. Brain 130: 521534.

Voss LJ, Jacobson G, Sleigh JW, Steyn-Ross A, Steyn-Ross M. 2009. Excitatory effects of gap junction blockers on cerebral cortex seizure-like activity in rats and mice. Epilepsia 50: $1971-1978$.

Wallraff A, Köhling R, Heinemann U, Theis M, Willecke K, Steinhäuser C. 2006. The impact of astrocytic gap junc- tional coupling on potassium buffering in the hippocampus. J Neurosci 26: 5438-5447.

Wang Y, Zaveri HP, Lee TS, Eid T. 2009. The development of seizures after continuous intrahippocampal infusion of methionine sulfoximine in rats: Avideo-intracranial electroencephalographic study. Exp Neurol 220: 293-302.

Williams DM, Lopes CM, Rosenhouse-Dantsker A, Connelly HL, Matavel A, Uchi J, McBeath E, Gray DA. 2010. Molecular basis of decreased Kir4.1 function in SeSAME/EAST syndrome. J Am Soc Nephrol 21: 21172129.

Wozny C, Gabriel S, Jandova K, Schulze K, Heinemann U, Behr J. 2005. Entorhinal cortex entrains epileptiform activity in CA1 in pilocarpine-treated rats. Neurobiol Dis 19: $451-460$.

Xiong ZQ, Stringer FL. 2000. Sodium pump activity, not glial spatial buffering, clears potassium after epileptiform activity induced in the dentate gyrus. J Neurophysiol 83: $1443-1451$.

Xu L, Zeng LH, Wong M. 2009. Impaired astrocytic gap junction coupling and potassium buffering in a mouse model of tuberous sclerosis complex. Neurobiol Dis 34: 291-299.

Yang S, Cox CL. 2011. Attenuation of inhibitory synaptic transmission by glial dysfunction in the rat thalamus. Synapse 65: 1298-1308.

Zhang H, Verkman AS. 2008. Aquaporin-4 independent Kir4.1 $\mathrm{K}^{+}$channel function in brain glial cells. Mol Cell Neurosci 37: 1-10.

Zurolo E, de Groot M, Iyer A, Anink J, van Vliet EA, Heimans JJ, Reijneveld JC, Gorter JA, Aronica E. 2012. Regulation of Kir4.1 expression in astrocytes and astrocytic tumors: A role for interleukin-1 $\beta$. J Neuroinflammation 9: 280 . 


\section{$\&_{\mathrm{CSH}}^{\infty} \&$ Cold Spring Harbor

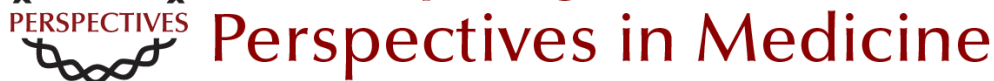

\section{Role of Astrocytes in Epilepsy}

Douglas A. Coulter and Christian Steinhäuser

Cold Spring Harb Perspect Med 2015; doi: 10.1101/cshperspect.a022434

Subject Collection Epilepsy: The Biology of a Spectrum Disorder

The Epilepsy Spectrum: Targeting Future Research Challenges

Gregory L. Holmes and Jeffrey L. Noebels

Role of Sodium Channels in Epilepsy

David I. Kaplan, Lori L. Isom and Steven Petrou

\section{Mechanisms of Action of Antiseizure Drugs and the Ketogenic Diet Michael A. Rogawski, Wolfgang Löscher and Jong M. Rho}

Epilepsy and Autism

Ashura W. Buckley and Gregory L. Holmes

Immunity and Inflammation in Epilepsy Annamaria Vezzani, Bethan Lang and Eleonora Aronica

Hyperpolarization-Activated Cyclic Nucleotide-Gated (HCN) Channels in Epilepsy Gary P. Brennan, Tallie Z. Baram and Nicholas P. Poolos

The Role of Calcium Channels in Epilepsy Sanjeev Rajakulendran and Michael G. Hanna Interneuron Transplantation as a Treatment for Epilepsy

Robert F. Hunt and Scott C. Baraban

\section{Common Mechanisms Underlying \\ Epileptogenesis and the Comorbidities of \\ Epilepsy \\ Andrey Mazarati and Raman Sankar}

The Diathesis-Epilepsy Model: How Past Events Impact the Development of Epilepsy and Comorbidities

Christophe Bernard

Potassium Channels in Epilepsy

Rüdiger Köhling and Jakob Wolfart

\section{GABAergic Synchronization in Epilepsy Roustem Khazipov \\ Status Epilepticus Syndi Seinfeld, Howard P. Goodkin and Shlomo Shinnar}

Neonatal and Infantile Epilepsy: Acquired and Genetic Models Aristea S. Galanopoulou and Solomon L. Moshé

Epigenetics and Epilepsy

David C. Henshall and Katja Kobow

Microcircuits in Epilepsy: Heterogeneity and Hub

Cells in Network Synchronization Anh Bui, Hannah K. Kim, Mattia Maroso, et al.

For additional articles in this collection, see http://perspectivesinmedicine.cshlp.org/cgi/collection/ 